\title{
Desenho e Validação de Primers In Silico para Detecção do Vírus Sincicial Respiratório Humano
}

\section{Design and Validation of Primers In Silico for Detection of Human Respiratory Syncytial Virus}

\author{
Jackson Alves da Silva Queiroz', Luciane Soares Alves', Deusilene Souza Vieira Dall'acqua², Luan Felipo \\ Botelho Souza ${ }^{3}$
}

\begin{abstract}
${ }^{1}$ Bacharel em Biomedicina - Faculdades Integradas Aparício Carvalho (FIMCA), ${ }^{2}$ Professora, Doutora - Faculdades Integradas Aparício Carvalho (FIMCA), ${ }^{2}$ Pesquisadora, Doutora - Fundação Oswaldo Cruz Rondônia (FIOCRUZ-RO), ${ }^{3}$ Professor, Mestre - Faculdades Integradas Aparício Carvalho (FIMCA)
\end{abstract}

\section{RESUMO}

Introdução: O desenvolvimento de primers é extremamente importante para pesquisas moleculares. Objetivos: $O$ presente estudo objetivou desenhar e validar primers in silico para detecção do vírus sincicial respiratório humano (RSVH). Materiais e Métodos: Foi construído um banco de 100 sequências de genoma completo do Vírus Sincicial Respiratório Humano (RSVH) depositadas no Genbank (NCBI). Realizado um alinhamento múltiplo global utilizando o algoritimo Clustal $W$, mapeadas as regiões conservadas e selecionado os primers. Posteriormente submetidos à análise dos parâmetros especificidade, pela ferramenta BLAST, concentração de GC\%, TMelting, comprimento, formação de dímeros e hairpin utilizando o software Oligo Analyser, validando-os para uso in vitro. Para discussão dos resultados, foram selecionados 14 primers de estudos realizados, submetidos à metodologia proposta neste estudo, comparando os dados obtidos. A região alvo escolhida foi o gene da Glicoproteína G, pela presença de sítios conservados. Resultados: Os primers amplificam um fragmento de $381 \mathrm{pb}$, que submetido a uma segunda PCR, resulta em $109 \mathrm{pb}$ correspondente ao tipo A do vírus e 168 pb para o tipo B, permitindo a detecção viral e a distinção de genótipos. Os primers possuem tamanho de 21 a 24 pb, com uma temperatura de melting entre $48,9 \circ \mathrm{C}$ e 55,3ㅇ. C. A concentração de GC\% varia de $33,3 \%$ a $52,4 \%$. O número de bases complementares na análise de dímeros e hairpin manteve-se abaixo de 5 bases. A Energia Livre de Gibbs (Delta G) acima de -9 kcal.mole(-1) como desejado. Conclusão: Os valores obtidos na validação dos primers estão em concordância com os já utilizados em estudos de referência, validando assim o seu uso in vitro. Palavras-chave: Desenho de primers. Bioinformática. Vírus Sincicial Respiratório. Análise In Silico. Dímeros. Hairpin.

\section{ABSTRACT}

Introduction: Developing primers is extremely important to molecular researches. Objectives: This study aims to drawing and validate in silico primers for detection of Human Respiratory Syncytial Virus (RSVH). Materials and Methods: It was built a database of 100 complete genome sequences of Human Respiratory Syncytial Virus (RSVH) deposited in the Genbank (NCBI), carried out a global multiple alignment using the algoritm Clustal W, thus mapping the conserved regions, and selecting primers, subsequently submitted to analysis of parameters such as specificity, by the BLAST tool, concentration of GC\% TMelting, length, and formation of dimers and hairpins using the software Oligo Analyser, validating them to use in vitro. For discussion of the results, we selected 14 primers of studies already carried out and submitted the methodology proposed in this study, comparing the data obtained. The selected target region was the gene encoding the Glycoprotein $G$, by the presence of conserved sites. Results: The primers selected amplifies a fragment of 381 bp in the 1st PCR, which subjected to a second PCR results in $109 \mathrm{bp}$ corresponding to the type $A$ of the virus and 168 base pairs for the type Bwhat allows not only viral detection, as the distinction of the type to which it belongs. The primers have size from 21 to 24 base pairs, having a melting temperature (Tmelting) between 48,9 $\mathrm{C}$ and 55,3 C and GC\% concentration ranging from $33.3 \%$ to $52.4 \%$. The number of complementary bases in the dimers and hairpins analysis was maintained below 5 bases, while the Gibbs free energy (Delta G) was kept above kcal.mole $-9(-1)$ as desired. Conclusion: All values obtained in the validation of the primers are in agreement with the ones already used in the reference studies, thereby validating its use in vitro.

Key words: Drawing primers, Bioinformatics, Respiratory Syncytial Virus, In Silico Analysis, Dimers, Hairpin.

\section{INTRODUÇÃO}

Desenvolvida em 1983 e que concedeu a Kary B. Mullis o Prêmio Nobel de química (MULLIS, 1990, SMITH; CANTOR, 1987) a técnica de Reação em Cadeia da Polimerase, PCR, têm crescido a cada dia como método de diagnóstico molecular para agentes infecciosos estando em constante avanço no meio científico e deve ser cada vez mais explorado (CAVALCANTI, 2008). Esta técnica, em estudos comparativos, apresenta uma maior eficiência e sensibilidade no diagnóstico de vírus respiratórios quando comparado com a técnica de 
Imunofluorescência (MINALI; DEBUR; FERRARI, 2015). O uso da técnica de multiplex PCR, uma variação da PCR, também já é uma realidade, permitindo a detecção de diferentes espécies de vírus em uma mesma reação (HAMMITT et al., 2011, COIRAS et al., 2003). Para realizar a PCR, alguns componentes são necessários, como DNTPs (Nucleotídeos) que irão compor a nova fita de DNA, tampão, responsável por proporcionar o pH ideal para a reação, a DNA Polimerase, enzima que sintetiza a nova fita e o cloreto de magnésio, cofator essencial para sua atividade (ALBERTS et al., 2002). Para que a Polimerase exerça sua função, é necessária a presença de oligonucleotídeos, denominados primers, que se ligam ao DNA alvo, indicando a região do genoma a ser amplificada (SAMBROOK; RUSSEL, 2001). Sendo assim, é imprescindível que se tenha um par de primers específico capaz de se ligar exclusivamente na região genômica de interesse, para se obter um produto de PCR que seja satisfatório (KUBISTA et al., 2006).

Graças ao avanço da bioinformática como ferramenta a ser utilizada nas pesquisas atuais (ARBEX; SILVA; COSTA, 2006) e ao gigantesco aumento de sequências depositadas no GenBank do NCBI (banco central de dados genômicos) desde 1982 (NCBI, 2015), pode-se dispor de ferramentas e softwares de bioinformática para aplicação no desenho de primers. Esta etapa é considerada como a mais importante de uma $\mathrm{PCR}$, pois a bioinformática propicia informações sobre os vírus, possibilitando selecionar genomas de diferentes países e a partir desses dados desenhar primers de alta qualidade, assegurando que os resultados da PCR sejam adequados (BEASLEY et al., 1999,
BUTLER; RUITBERG; VALLONE, 2001). Ao desenhar primers, deve-se compreender o conceito do alinhamento de sequências, essencial para a realização de tarefas mais complexas. O software busca meios de alinhá-las, inserindo espaços em posições arbitrárias de maneira que haja correspondência dos nucleotídeos semelhantes, levando em conta o grau de semelhança entre elas, permitindo então a visualização das regiões conservadas e variáveis (SETUBAL; MEIDANIS, 1997). Para isso os softwares utilizam de algoritmos desenvolvidos ao longo do tempo, como por exemplo, o FASTA e o BLAST, úteis também na pesquisa de DNA, sequências e proteínas. Existem outras opções mais atuais, modernas e mais sensíveis, porém que demandam computadores com hardware potente (PEARSON; LIPMAN, 1988, ALTSCHUL et al., 1990).

Entre os tipos de alinhamento mais utilizados, encontra-se o do tipo global e o local. No global, o algoritmo busca o melhor alinhamento entre sequências inteiras, sendo aplicado quando se tem sequências similares e de tamanho parecido, e recomendado, por exemplo, na análise de mutações por trocas de bases. No Alinhamento local, o algoritmo busca regiões conservadas entre elas, alinhando-as, porém este possui uma maior utilidade quando se tem sequências de tamanhos diferentes (PERANCONI, 2005). Para que os primers sejam específicos e proporcionem um bom resultado na PCR é necessário que sua composição não favoreça a formação de estruturas indesejáveis, o que impede a sua ligação com o DNA alvo. Entre tais estruturas, pode ser citado o hetero-dímero, estrutura formada pela presença de muitas bases complementares entre os pares 
de primers, influenciada diretamente pelo comprimento do primer (WANG; SEED, 2003). A temperatura de melting também é um fator importante, por ser relacionada à temperatura necessária para dissociação das fitas sintetizadas na PCR, sendo necessário que haja equivalência entre os diferentes iniciadores (BROWN, 2003).

A formação de hairpin (auto anelamento) deve ser evitada com a análise das bases complementares na composição do primer e da Tmelting que possibilite essa ligação (SANTORO, 2008). Outra característica é a distribuição de bases nitrogenadas, Guanina e Citosina, que pela sua ligação estável podem interferir elevando a temperatura de dissociação, bem como a alta quantidade de Adenina e Timina que leva a sua diminuição (LEHNINGER; NELSON; COX, 2000).

Os softwares de bioinformática possibilitam a análise destes parâmetros, permitindo o desenho de primers para detecção de diversos agentes. Neste estudo, o agente escolhido como modelo foi o Vírus Sincicial Respiratório Humano (RSVH). RSVH foi isolado no ano de 1956, por Morris, em chimpanzés denominados inicialmente como causador da Coriza do Chimpanzé, devido aos sintomas respiratórios observados na espécie em questão e foi associado. No ano seguinte, por Chanock e seus colaboradores a infecções humanas, por notarem a semelhança dos sintomas dos animais com os apresentados em duas crianças (BEEM et al., 1960, KOPELMAN; MIYOSHI, 1999).

Este é relacionado a Infecções Respiratórias Agudas, (IRAs) que podem ser causados por vários agentes biológicos (MACEDO et al., 2003), dentre os quais outros agentes virais são descritos como o vírus Influenza, sorotipo A e B, Parainfluenza, Coronavírus, Adenovírus, Rinovírus e Bocavírus (DUNN, J. J; MILLER, 2014). Segundo dados da OPAS/OMS cerca de $40 \%$ a $60 \%$ das consultas ambulatoriais pediátricas têm como motivo as infeções respiratórias agudas, (IRAs) (BRASIL, 1991, MACEDO et al., 2003), sendo uma das principais causas de mortalidade em crianças menores de 5 anos no Brasil (BRASIL, 1993), e ao lado de doenças diarreicas são responsáveis por cerca de 2 milhões de mortes por ano no mundo (WILLIAMS et al., 2002).

O RSVH é um dos principais vírus respiratório descrito em países em desenvolvimento, estando relacionado com diversos fatores socioeconômicos e ambientais (BERMAN, 1991), sendo também altamente incidente a nível nacional, já retratado desde a década de 1980 em diversos estudos (SUTMOLLE et al., 1995, MIYAO et al., 1999, MOURA et al., 2003).

O vírus se multiplica nas vias aéreas superiores, desencadeando processos inflamatórios, ocasionando lesões do tecido mucoso (HALL; DOUGLAS, 1991), e ao atingir as vias aéreas inferiores desenvolvem quadros de bronquiolite e pneumonia, sendo estas as manifestações mais comuns (WELLIVER, 1998), porém seu agravo depende de alguns fatores de predisposição (ALVAREZ et al., 2013).

O RSVH pertencente ao gênero Pneumovírus e à família Paramixoviridiae, apresenta uma estrutura envelopada, esférica e com um diâmetro de aproximadamente $150 \mathrm{~nm}$ (Figura 1). Mais internamente encontra-se um genoma linear composto de RNA fita simples de carga negativa, 
Figura 1. Estrutura do Vírus sincicial respiratório e o seu genoma composto de 10 genes e suas respectivas proteínas codificadas.
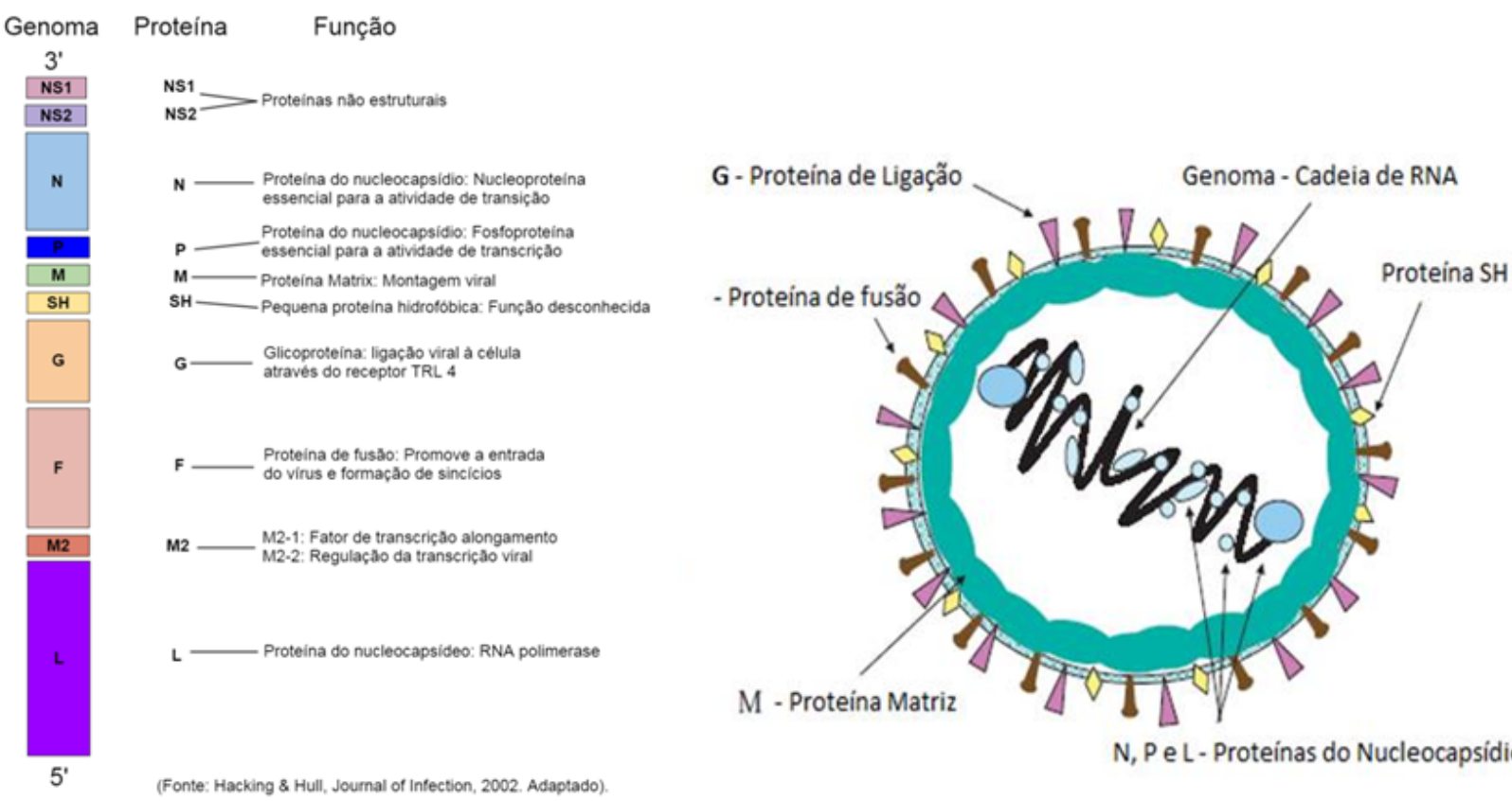

N, P e L - Proteínas do Nucleocapsídio

de tamanho aproximado de $15 \mathrm{~kb}$, que codifica 10 proteínas, sendo oito estruturais (N, P, M, SH, F, G, $M 2, L)$ e 2 não estruturais (NS1, e NS2) (EXPASY, 2015). O Gene G codificador da Glicoproteína é responsável pela ligação do vírus à célula hospedeira para o início da replicação, e também é o gene que apresenta a maior variabilidade entre os grupos A e B do vírus, e o Gene L, maior gene, codificador da enzima Polimerase, é o que detém os sítios mais conservados do genoma, tanto pra variante $A$ quanto para a $B$ do vírus (MACHADO, 2012).

Partindo de todos esses princípios, a presente pesquisa teve como objetivo desenhar e validar primers in silico para a detecção do Vírus Sincicial Respiratório Humano (RSVH), dispondo de ferramentas de bioinformática gratuitas, sendo realizado em três etapas: $A$ análise do genoma viral para mapeamento das regiões conservadas, seguido da seleção dos primers candidatos, e por último a validação in sílico.

\section{MATERIAIS E MÉTODOS}

A busca das sequências referência de genoma completo, se deu no Genbank do National Center for Biotechnology Information (NCBI). Na guia RefSeq Home, utilizou-se a expressão "human respiratory syncytial vírus complete genome" como palavra-chave. As cepas resultantes desta busca foram selecionadas, de modo que houvesse representantes de diversos países. O total foi de 100 cepas, sendo 50 do RSV tipo A e 50 do tipo B, exibidas no formato Genbank. Estas foram convertidas para o formato FASTA Text no próprio sistema do banco de dados e realizado $\mathrm{o}$ Download. As sequências foram agrupadas e exportadas para um software de edição de textos simples (bloco de notas do sistema operacional Windows), dando origem a dois bancos de sequências, um contendo as do tipo $A$ e outro as do tipo B. Cada uma foi devidamente identificada com o local de origem, seu respectivo código de identificação no GenBank, e o tipo viral a qual 
pertence, RSV A ou B. Para o alinhamento, foi utilizado o software MEGA6 (Molecular Evolutionary Genetics Analysis Version 6.0), onde se criou um documento novo de alinhamento de DNA, e adicionado os dois bancos de sequências resultantes do passo anterior. $\mathrm{O}$ algoritmo utilizado foi o Clustal W contido no próprio software Mega6, que realiza alinhamento do tipo Múltiplo global.

Por meio do alinhamento foram analisadas as regiões do genoma quanto a sua conservação ou variabilidade. Foi dado prioridade ao Gene G e L, pelo seu relato na literatura como genes que contem regiões conservadas (MACHADO, 2012). As regiões semelhantes em ambos os tipos virais serviram para o desenho de primers capazes de detectar o Sincicial Respiratório, enquanto as regiões exclusivas do tipo $A$ ou $B$, para o desenho de primers que diferenciassem os genótipos.

Os primers foram selecionados observando alguns parâmetros como critérios de inclusão ou exclusão. A região escolhida deveria apresentar cerca de 20 nucleotídeos e uma boa distribuição de bases guanina e citosina, no máximo $60 \%$ para evitar a elevação da temperatura de anelamento e dissociação. As regiões com muitas adeninas e timinas também foram evitadas para não haver a diminuição dos mesmos.

A validação final foi feita com uso da ferramenta online Oligo Analyzer 3.1. Foi verificada a possível formação de self dímeros, hetero-dimeros e hairpin. $\mathrm{Na}$ análise de dímeros, os primers não poderiam apresentar energia livre de Gibbs abaixo de $-9 \mathrm{kcal} / \mathrm{mole}-1$, ou muitas bases complementares. Na análise de Hairpin, além dos valores de Delta $G$, foi verificada a temperatura de melting que possibilitasse o auto anelamento, sendo recomendado valores inferiores a 50 ㅇ C.

A Tmelting foi calculada estimando-se que os valores entre cada par de primers fossem próximos, visando posteriormente estabelecer uma média na padronização da PCR. As temperaturas não poderiam ser tão divergentes, sendo que no caso de alta variação, foram excluídas ou acrescentadas algumas bases na sequência do primer, até se obter um resultado satisfatório.

\section{RESULTADOS}

A análise do genoma do Vírus Sincicial Respiratório através do alinhamento permitiu a confirmação do que a literatura descreve em relação à presença de sítios conservados localizados no gene da Polimerase (Gene L) e o gene da Glicoproteína de superfície (Gene G) (MACHADO, 2012). A região alvo escolhida para desenho foi o Gene G, pela presença de regiões conservadas que distinguiam os tipos virais, e pela boa distribuição de GC. Várias regiões dentro do gene foram selecionadas, e calculadas o possível tamanho do fragmento de amplificação na PCR, até que se pudesse chegar a um conjunto de primers que se encaixassem nos parâmetros descritos na metodologia.

Os primers escolhidos apresentam um tamanho de aproximadamente $21 \mathrm{pb}$, sendo que as sequências respectivas, bem como a posição no gene de interesse estão descritas na Tabela 1. As temperaturas de fusão (Tmelting) apresentam um intervalo entre $48,9 \circ \mathrm{C}$ e $55,3 \circ \mathrm{C}$ e a concentração de GC\%, de 33,3\% a 52,4\%, com uma variação entre os pares de no máximo $5^{\circ} \mathrm{C}$. 


\section{Primers HRSV}

Posição

HRSV-1 150 a 170

HRSV-A 236 a 259

HRSV-B 295 a 318

HRSV-2 511 a 531
Sequência 5' - 3'

TTTGGCAATGATAATCTCAAC

GGCTTGTTGCATCTTGTATGATTG

GCTAACCCTTTCTGGTGAGAC

GGGYACAAAGTTGAACACTTC
Sentido Melt Temp

$\%$ GC

Sense

$48,9^{\circ} \mathrm{C}$

33,3

Antisense $\quad 55^{\circ} \mathrm{C}$

41,7

Antisense

$55,3^{\circ} \mathrm{C}$

52,4

Antisense $\quad 53^{\circ} \mathrm{C}$

45,2
Estes iniciadores foram desenhados propondo sua utilização em duas PCRs. Na 1a PCR utiliza-se os primers RSV-1 e RSV-2 que amplificam um fragmento de 381 pares de base. O fragmento resultante desta etapa é submetido a 2a $\mathrm{PCR}$, uma Semi-Nested, onde mantém-se o primer Sense RSV1, e acrescenta-se dois primers Antisense distintos, RSV-A e RSV-B. Caso o vírus pertença ao tipo A, na segunda PCR, amplifica-se um fragmento de 109 $\mathrm{pb}$, e caso pertença ao tipo $\mathrm{B}, \mathrm{o}$ fragmento amplificado é de 168 pares. O uso de primers Antisense distintos para cada variante viral, permite essa diferenciação, por meio de diferentes tamanhos de fragmentos, possibilitando assim a genotipagem os isolados. As 100 sequências obtidas do Genbank para o alinhamento múltiplo, e utilizadas no desenho dos primers estão ilustradas na árvore filogenética (Figura 2). Cada uma devidamente identificada com o código de identificação do banco de dados, o local de origem onde foi isolado, e o tipo viral a qual pertence, destacadas em vermelho as sequências pertencentes ao tipo $A$, e em verde ao tipo $B$. Para ilustração do alinhamento, foram selecionadas 21 sequências, das 100 obtidas, tendo o cuidado de comtemplar todas as diferentes localidades, e alinhadas com cada primer, permitindo a visualização da região de ligação destes (Figuras 36). As regiões alvos são altamente conservadas e com algumas mutações pontuais. A análise de especificidade foi realizada com o auxílio do alinhamento simples local no BLAST (NCBI) (Figuras 7-10). Verificou-se a especificidade dos primers na detecção somente do vírus de interesse, e o seu gene alvo (Gene $\mathrm{G}$ ). Os valores de identidade foram de $100 \%$, representando uma alta especificidade. Destacado como exceção, o primer RSV-2 obteve um valor de identidade de $95 \%$, o que pode ser explicado pela presença de uma base degenerada em sua composição (Tabela 1). Entretanto, este valor ainda é relevante, o que não compromete de maneira significativa sua eficiência.

Nas figuras 7 e 10 verifica-se que os primers RSV 1 e 2 são específicos para a região do Gene G. A distinção dos genótipos pelos primers Antisense usados na Semi-Nested também ficam evidentes (Figura 8 e 9), onde os primers A e B se mostram específicos para a detecção do tipo viral para o qual foram desenvolvidos. Na análise da formação de hairpin, os resultados também foram favoráveis. A análise realizada pelo software 


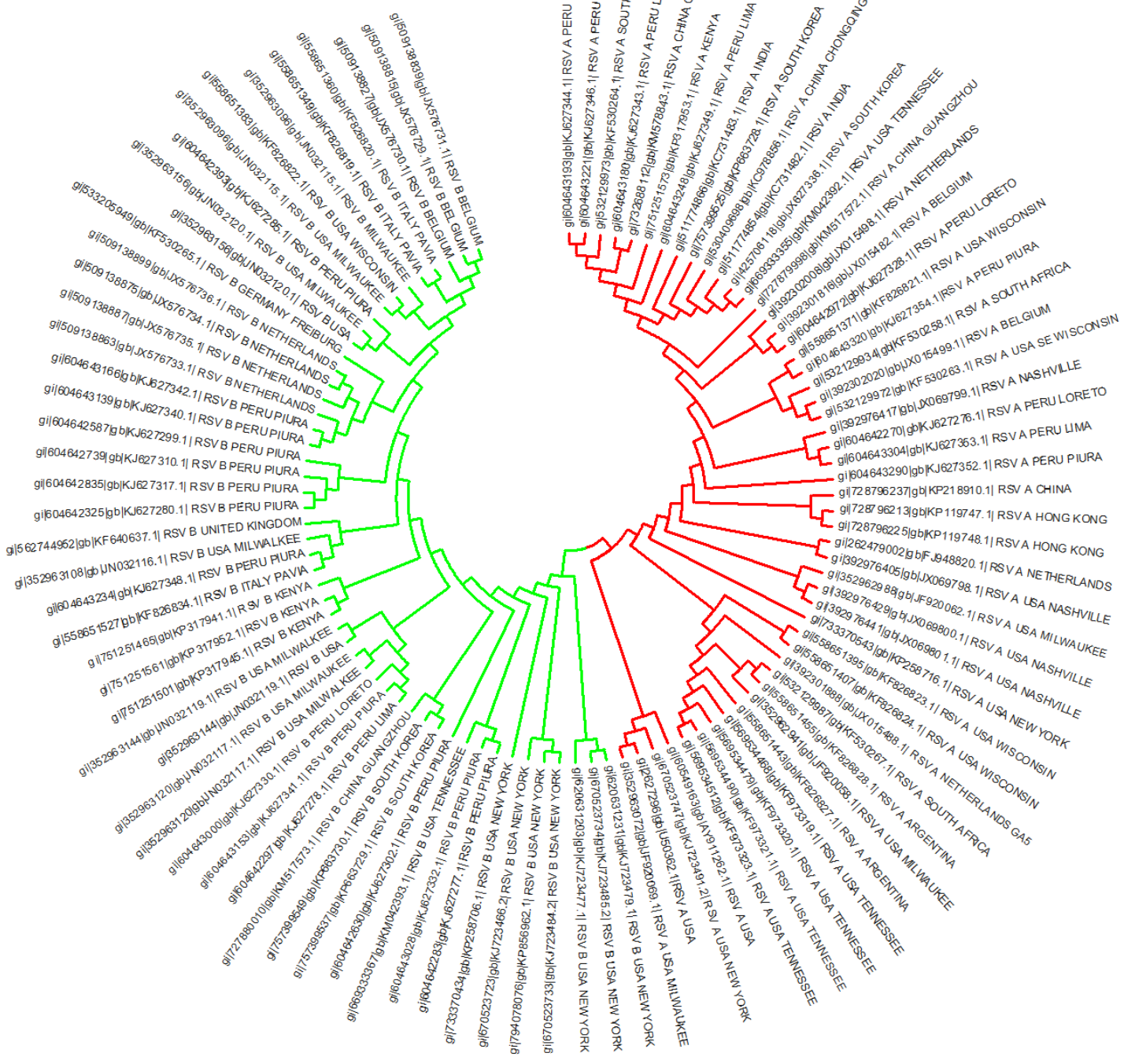

Figura 2. Representação genômica dos vírus A e B, por meio de árvore filogenética.

apresenta a possível estrutura formada, o valor de Delta $G$, e a Temperatura de melting necessários para que ocorra a formação deste arranjo (Figura 11). As temperaturas de melting mantiveram-se abaixo de 43,8 C, sendo necessário evitar tais valores na padronização da reação. Os valores de Delta $\mathrm{G}$ não ultrapassaram limiar de-9Kcal.mole ${ }^{-1}$, conforme esperado. Quanto aos resultados referentes à avaliação de self dímeros (Figura 12) e hetero dímeros (Figura 13), observou-se que os primers em questão apresentaram um número de bases complementares variando entre 3 e 5 bases seguidas. Assim como na análise de hairpin, os valores de Delta G permaneceram acima de -9 kcal.mole ${ }^{-1}$. A análise de hetero-dimeros foi feita levando em conta a possível interação entre os pares de primers nas duas PCR.

Para comparar os resultados obtidos, foram selecionados 14 sequências de primers empregados em diversos estudos para detecção do Vírus Sincicial Respiratório por meio de PCR convencional ou PCR em Tempo Real (Tabela 2). Estes iniciadores foram avaliados conforme os parâmetros descritos nesta metodologia, fazendo uso das mesmas ferramentas. Os primers na posição 1 à 14 são descritos nos estudos de 


\begin{tabular}{|c|c|}
\hline . RSV 1 & \\
\hline . gi|392976417|gb|JX069799.1| RSV A NASHVILLE & AATCACATTATCTATTTTGGCAATGATAATCTCAACTTCACT' \\
\hline . gi|392302020|gb|JX015499.1| RSV A BELG] & АТTCACATTATCTATTTTGGCAATGATAATCTCAACTTCACT' \\
\hline 4. gi|511774854|gb|KC731482.1| RSV A INDIA & ATCACATTATCTATTTTGGCAATGATA \\
\hline . gi|392302008|gb|JX015498.1| RSV A NETHE: & ATCACATTATCTATTTTGGC \\
\hline . gi|530409698|gb|KC978856.1| RSV A CHINA CHONGQ & ATCACATTATCTATTTTGGC \\
\hline 7. gi|604643180|gb|KJ627343.1| RSV A PERU LORETO & ААTCACATTATCTAT? \\
\hline 8. gi|532129934|gb|KF530258.1| RSV A SOUTH AFRICA & АTCACATтATCTAT \\
\hline 9. gi|670523747|gb|KJ723491.2| RSV A USA NEW YORK & ATCAC \\
\hline 10. gi|728796213/gb|KP119747.1| RSV A HONG KONG & ATCAC \\
\hline 11. gi|751251573|gb|KP317953.1| RSV A KENYA & ATCAC \\
\hline 12. gi|533205949|gb|KF530265.1| RSV B GERMANY FRE & AATAGC \\
\hline 13. gi|558651349|gb|KF826819.1| RSV B ITALY PAVIA & ATAGC \\
\hline 14. gi|352963120|gb|JN032117.1| RSV B USA MILWAU: & ATAGC \\
\hline 15. gi|509138815|gb|JX576729.1| RSV B BELGIUM & ATAGC \\
\hline 6. gi|509138863|gb|JX576733.1| RSV B NETH & ATAGC \\
\hline 17. gi|562744952|gb|KF640637.1| RSV B UNITED KIN & ATAG \\
\hline 18. gi|604642297|gb|KJ627278.1| RSV B PERU LIMA & \\
\hline 9. gi|727880010|gb|KM517573.1| RSV B CHINA GUAN & \\
\hline 20. gi|751251561|gb|KP317952.1| RSV B KENYA & \\
\hline 1. gi|757399549|gb|KP663730.1| RSV B SOUTH KOR & \\
\hline 2. gi|620631203|gb|KJ723477.1| RSV B USA NEW YORK & \\
\hline
\end{tabular}

Figura 3. Alinhamento do primer RSV 1 usando o software MEGA6 demonstra alta semelhança com as sequências escolhidas do

RSV A e B na posição 150 a 170 do gene G.

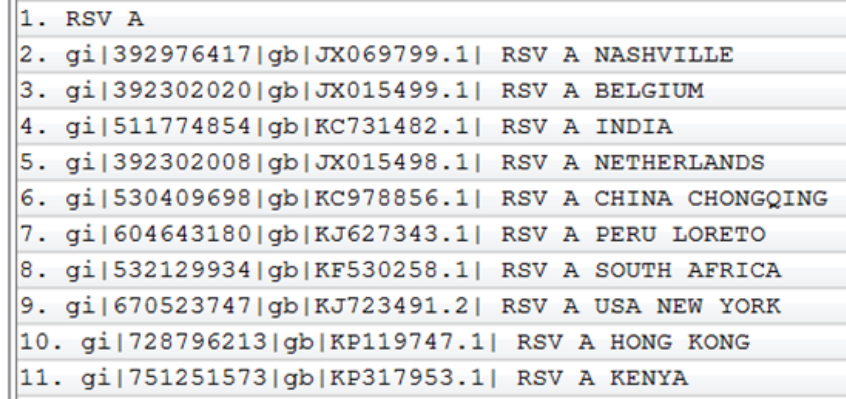

\begin{tabular}{|c|}
\hline$-\cdots-\cdots-\cdots$ - CAATCATACAAGATGCAACAAGCC $-\cdots \cdots$ \\
\hline САСТАACAACTGCAATCATACAAGATGCAACAAACCAGATCAA \\
\hline СACTAACAACTGCAATCATACAAGATGCAACGAACCAGATCAA \\
\hline САCTAACAACTGCAATCATACAAGATGCAACGAACCAGATCAA \\
\hline САCTAACAACTGCAATCACACAAGATGCAACGAACCAGATCAA \\
\hline CACTAACAACTGCAATCATACAAGATGCAACGAACCAGATCAA \\
\hline САCTAACAACTGCAATCACACAAAATGCAACGAACCAGATCAA \\
\hline САCTAACAACTGCAATTATACAAGATGCAACGAACCAGATCAAI \\
\hline САТСАACAACTACAATCATACAAGATGCAACAAACCAGATCAA \\
\hline САСТAACAACTGCAATCATACAAGTTGCAACAAACCAGGTCAAI \\
\hline CACTAACAACTGCAATCATACAAGATGCAACGAACCAGATCAZ \\
\hline
\end{tabular}

Figura 4. Alinhamento do primer RSV A usando o software MEGA6 demonstra alta semelhança com as sequências escolhidas do

RSV A na posição 236 a 259 do gene G.

11. RSV B

12. gi|533205949|gb|KF530265.1| RSV B GERMANY FREIBURG 13. gi|558651349|gb|KF826819.1| RSV B ITALY PAVIA

14. gi|352963120|gb|JN032117.1| RSV B USA MILWAUKEE 15. gi|509138815|gb|JX576729.1| RSV B BELGIUM 16. gi|509138863|gb|JX576733.1| RSV B NETHERLANDS 17. gi|562744952|gb|KF640637.1| RSV B UNITED KINGDOM 18. gi|604642297|gb|KJ627278.1| RSV B PERU LIMA 19. gi|727880010|gb|KM517573.1| RSV B CHINA GUANGZHOU 20. gi|751251561|gb|KP317952.1| RSV B KENYA 21. gi|757399549|gb|RP663730.1| RSV B SOUTH KOREA 22. gi|620631203|gb|RJ723477.1| RSV B USA NEW YORK

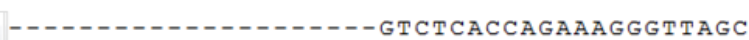
ATAACCACTTACCTTACTCAAGTCTCACCAGAAAGGGTTAGCCCATCC: ATAACCACTTACCTTACTCAAGTCTCACCAGAAAGGGTTAGCCCATCC: ATAACCACTIACCTTACTCAAGTCTCACCAGAAAGGGTTAGCCCATCC: ATAACCACTTACCTTACTCAAGTCTCACCAGAAAGGTTAGCCCATCC: ATAACCACTTACCTTACTCAAGTCTCACCAGAAAGGGTTAGCCCATCC: ATAACCACTTACCTTACTCAAGTCTCACCAGAAAGGGTTAGCCCATCC: ATAACCACTTACCTTACTCAAGTCTCACCAGAAAGGGTTAGCCCATCC: ATAACCACTTACCTTACTCAAGTCTCACCAGAAAGGGTTAGCCCATCC: ACAACCACTTACCTTACTCAAGTCTCACCAGAAAGGGTTAGCCCATCC: ATAACCACTTACCTTACTCAAGTCTCACCAGAAAGGGTTAGCCCATCC: ATCACTACCTACCTTACTCAAGTCCCACCAGAAAGGGTTAGCTCATCC:

Figura 5. Alinhamento do primer RSV B usando o software MEGA6 demonstra alta semelhança com as sequências escolhidas do RSV B na posição 295 a 318 do gene $G$.

\begin{tabular}{|c|c|}
\hline . RSV 2 & \\
\hline 2. gi|392976417|gb|JX069799.1| RSV A NASHVILLE & AATGATTTTCACTTTGAAGTGTTCAATTTTG? \\
\hline 3. gi|392302020|gb|JX015499.1| RSV A BE & ATGATTTTCACTTTGAAGTGTTCAATTTTGT. \\
\hline 4. gi|511774854|gb|RC731482.1| RSV A INDIA & ATGATTTTCACTTTGAAGTGTTCAATTTTGT \\
\hline 5. gi|392302008/gb|JX015498.1| RSV A NETHERLANDS & ATGATTTTCACTTTGAAGTGTTCA \\
\hline 6. gi|530409698|gb|RC978856.1| RSV A CHINA C: & ATGATTTTCACTTTG \\
\hline 7. gi|604643180|gb|RJ627343.1| RSV A PERU LORETO & TGATTTTCACTTI \\
\hline 8. gi|532129934|gb|KF530258.1| RSV A SOUTH AFRICA & TGATT \\
\hline 9. gi|670523747|gb|RJ723491.2| RSV A USA NEW YORE & TG: \\
\hline 10. gi|728796213|gb|KP119747.1| RSV A HONG KONG & GTGTTC \\
\hline 11. gi|751251573|gb|RP317953.1| RSV A KENYA & ATGATT \\
\hline 12. gi|533205949|gb|KF530265.1| RSV B GERMANY FREIB & ATGATT \\
\hline 1349|gb|KF826819.1| RSV B ITALY PAVIA & \\
\hline 14. gi|352963120|gb|JN032117.1| RSV B USA MILWAU & \\
\hline 15. gi|509138815/gb|JX576729.1| RSV B BELGIUM & $T G A$ \\
\hline 16. gi|509138863|gb|JX576733.1| RSV B NETHERLAN & ATGATTA \\
\hline 17. gi|562744952|gb|RF640637.1| RSV B UNITED KING & ATGATTACCATTTT \\
\hline 18. gi|604642297|gb|KJ627278.1| RSV B PERU LIMA & ATGATTACCATTTTGAAGTGTCA \\
\hline 19. gi|727880010|gb|KM517573.1| RSV B CHINA GUANGZHOt & ATGATTACCATTTTGAAGTGTTC: \\
\hline 10. gi|751251561|gb|KP317952.1| RSV B KENYA & \\
\hline 1. gi|757399549/gb|KR663730.1| RSV B S & \\
\hline & \\
\hline
\end{tabular}

Figura 6. Alinhamento do primer RSV 2 usando o software MEGA6 demonstra alta semelhança com as sequências escolhidas do RSV A e B na posição 511 a 531 do gene G. 
Figura 7. Alinhamento local do primer RSV 1 no software BLAST do NCBI demonstrando $100 \%$ de identidade do primer com as cepas de interesse (Fonte: $\mathrm{NCBI}$ ).

\begin{tabular}{|c|c|c|c|c|c|c|}
\hline Description & $\begin{array}{l}\text { Max } \\
\text { soore }\end{array}$ & $\begin{array}{l}\text { Total } \\
\text { soore }\end{array}$ & $\begin{array}{l}\text { Query } \\
\text { cover }\end{array}$ & $\underset{\text { value }}{\mathrm{E}}$ & Ident & Accession \\
\hline 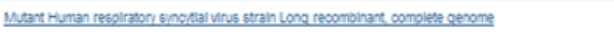 & 48.1 & 48.1 & $100 \%$ & 0.002 & $100 \%$ & Kuา07921.1. \\
\hline & 48.1 & 48.1 & $100 \%$ & 0.002 & $100 \%$ & KU3161801 \\
\hline & 48.1 & 48.1 & $100 \%$ & 0.002 & $100 \%$ & KU316178 \\
\hline 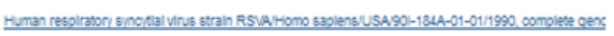 & 48.1 & 48.1 & $100 \%$ & 0.002 & $100 \%$ & KU316176.1 \\
\hline 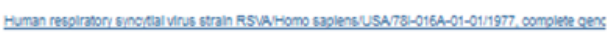 & 48.1 & 48.1 & $100 \%$ & 0.002 & $100 \%$ & Kus16171.1 \\
\hline 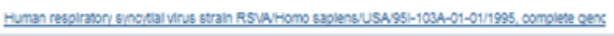 & 48.1 & 48.1 & $100 \%$ & 0.002 & $100 \%$ & $\underline{\text { Ku316170 }}$ \\
\hline Human respiraton s. & 48.1 & 48.1 & $100 \%$ & 0.002 & $100 \%$ & \\
\hline 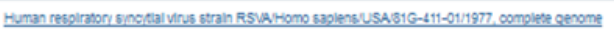 & 48.1 & 48.1 & $100 \%$ & 0.002 & $100 \%$ & \\
\hline 344-01-011993, complete gen & 48.1 & 48.1 & $100 \%$ & 0.002 & $100 \%$ & $\underline{\text { KU316161.1 }}$ \\
\hline 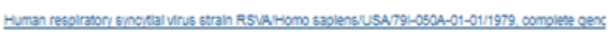 & 48.1 & 48.1 & $100 \%$ & 0.002 & $100 \%$ & $\underline{\text { KU316157.1 }}$ \\
\hline 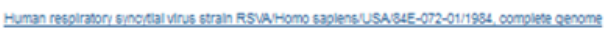 & 48.1 & 48.1 & $100 \%$ & 0.002 & $100 \%$ & KU3161L81 \\
\hline 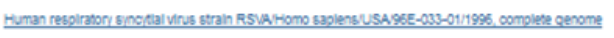 & 48.1 & 48.1 & $100 \%$ & 0.002 & $100 \%$ & KU316145: \\
\hline 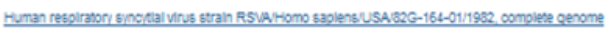 & 48.1 & 48.1 & $100 \%$ & 0.002 & $100 \%$ & Kus161431 \\
\hline 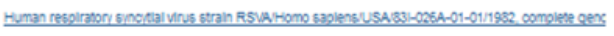 & 48.1 & 48.1 & $100 \%$ & 0.002 & $100 \%$ & $\underline{\text { KU3161421 }}$ \\
\hline 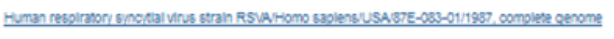 & 48.1 & 48.1 & $100 \%$ & 0.002 & $100 \%$ & Ku3161381 \\
\hline 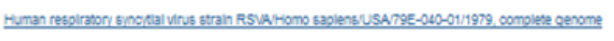 & 48.1 & 48.1 & $100 \%$ & 0.002 & $100 \%$ & $\underline{\text { Ku316137.1. }}$ \\
\hline
\end{tabular}

Figura 8. Alinhamento local do primer RSV A no software BLAST do NCBI demonstrando $100 \%$ de identidade do primer com as cepas de interesse (Fonte: NCBI).

Abels et al. 2001, Hu et al. 2002, Jokela et al. 2010, Whiley et al. 2002 e Zlateva et al. 2007. Apenas as informações referentes a sequência dos primers retirados destes estudos foram extraídas. Os valores dos parâmetros apresentados nesta tabela correspondem à análise seguindo esta metodologia. Os primers na posição 15 a 18 são os mesmos descritos na Tabela 1.

\section{DISCUSSÃO}

Analisando os resultados da Tabela 2, em análise geral, pode ser verificado que os valores obtidos na avaliação dos parâmetros estão em concordância com os estudos já realizados. É importante ressaltar que os primers desses autores já foram utilizados in vitro, e obtiveram ótimos resultados (ABELS et al., 2001, HU et al., 2002, JOKELA et al., 2010, WHILEY et al., 2002 e ZLATEVA et al., 2007). De maneira mais descritiva, pode ser observado que os valores da concentração de GC dos primers se mantiveram abaixo de $60 \%$ conforme recomendado. Observando o primer 10, é possível verificar a influência da sua concentração de GC, que foi de $53,48 \%$, no aumento da temperatura de melting que é de $62,9^{\circ} \mathrm{C}$, uma correlação já descrita na literatura pela estável ligação de bases 


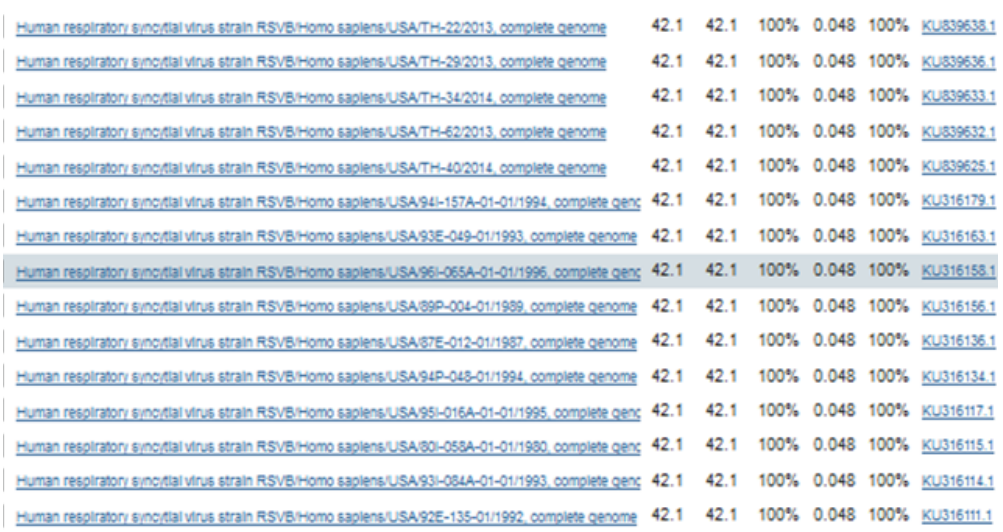

Figura 9. Alinhamento local do primer RSV B no software BLAST do NCBI demonstrando $100 \%$ de identidade do primer com as cepas de interesse (Fonte: $\mathrm{NCBI})$.

\begin{tabular}{|c|c|c|c|c|c|c|}
\hline Description & $\begin{array}{l}\text { Max } \\
\text { score }\end{array}$ & $\begin{array}{l}\text { Total } \\
\text { score }\end{array}$ & $\begin{array}{l}\text { Query } \\
\text { cover }\end{array}$ & $\underset{\text { value }}{E}$ & Ident & Accession \\
\hline 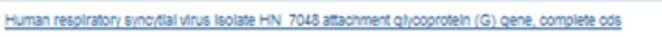 & 39.4 & 39.4 & $100 \%$ & 0.32 & $95 \%$ & KT7814041 \\
\hline 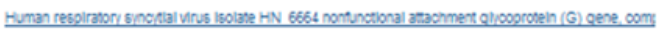 & 39.4 & 39.4 & $100 \%$ & 0.32 & $95 \%$ & KT7814021 \\
\hline Human resgiraton songela & 39.4 & 39.4 & $100 \%$ & 0.32 & $95 \%$ & $\underline{\mathrm{KT} 7813981}$ \\
\hline 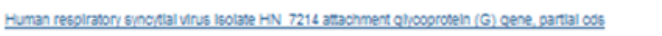 & 39.4 & 39.4 & $100 \%$ & 0.32 & $95 \%$ & $\underline{K T 781392.1}$ \\
\hline 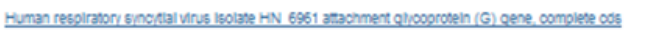 & 39.4 & 39.4 & $100 \%$ & 0.32 & $95 \%$ & $\underline{\mathrm{KT}} 781381.1$ \\
\hline 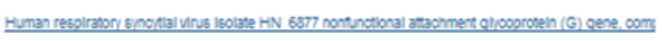 & 39.4 & 39.4 & $100 \%$ & 0.32 & $95 \%$ & KT781379.1 \\
\hline 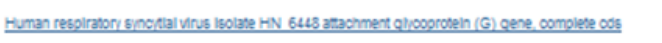 & 39.4 & 39.4 & $100 \%$ & 0.32 & $95 \%$ & $\underline{\mathrm{KT} 731377.1}$ \\
\hline 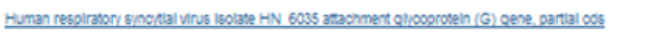 & 39.4 & 39.4 & $100 \%$ & 0.32 & $95 \%$ & $\underline{\mathrm{KT}} \mathbf{3} 1373.1$ \\
\hline 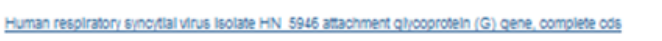 & 39.4 & 39.4 & $100 \%$ & 0.32 & $95 \%$ & $\underline{\mathrm{KT} 7813701}$ \\
\hline 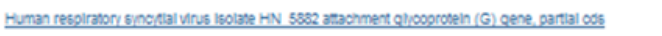 & 39.4 & 39.4 & $100 \%$ & 0.32 & $95 \%$ & $\underline{\mathrm{KT}} \mathbf{3 1 3 8 9 . 1}$ \\
\hline Human tespiratost & 39.4 & 39.4 & $100 \%$ & 0.32 & $95 \%$ & KT7513631 \\
\hline
\end{tabular}

Figura 10. Alinhamento local do primer RSV 2 no software BLAST do NCBI demonstrando $100 \%$ de identidade do primer com as cepas de interesse (Fonte: NCBI).

GC (LEHNINGER; NELSON; COX, 2000). A temperatura de melting variou entre $51^{\circ} \mathrm{C}$ e $63^{\circ} \mathrm{C}$, sendo a maior temperatura correspondente ao primer 10, e o de menor valor, correspondente ao primer 2. Os intervalos das temperaturas entre os pares de primers não ultrapassaram os $5^{\circ} \mathrm{C}$, facilitando a escolha de uma média para a etapa de anelamento da PCR. Quanto ao comprimento, os tamanhos variam de 20 a 30 nucleotídeos, onde os maiores atingem uma extensão de 29 e 30 nucleotídeos (HACKING; HULL, 2002, JOKELA et al., 2010). Primers de alta extensão devem ser evitados pois favorecem a presença de bases complementares (WANG; SEED, 2003).

Os valores observados na análise de especificidade pelo BLAST foram equivalentes, sendo que todos apresentaram alta especificidade onde a maioria atingiu valores de $100 \%$, o restante com resultados de $96 \%$. Apenas o primer 18 atingiu 95\% de identidade, e atribui-se este valor a presença de uma base degenerada em sua composição.

Ao comparar os valores de Delta $G(\Delta G)$ na análise de self-dímeros, pode-se verificar uma variação de $-3,14$ a $-9,5$ kcal.mole ${ }^{-1}$. Durante a realização desta avaliação, esperava-se encontrar valores positivos, porém verificou-se que os demais estudos analisados também apresentavam valores negativos, entretanto nenhum menor que -9 kcal.mole ${ }^{-1}$ como era previsto, com exceção do primer 7 que atingiu $-9,5$ kcal.mole ${ }^{-1}$, o que possibilitaria a formação de um self-dimero. Semelhantemente, o Delta G correspondente à 

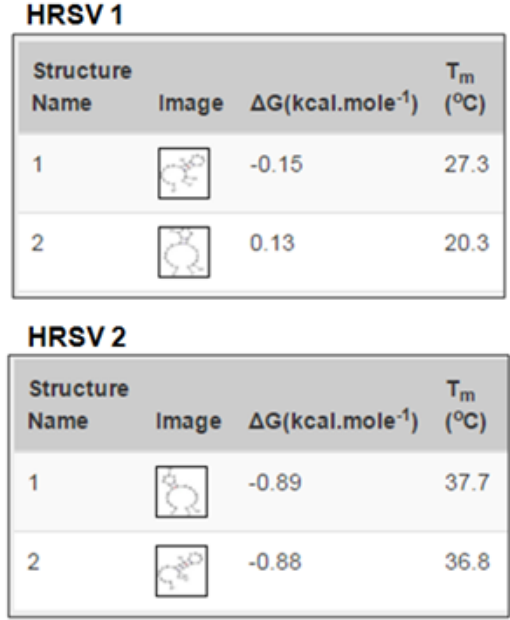

HRSV A

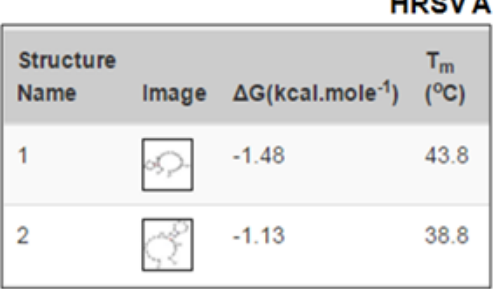

HRSV B

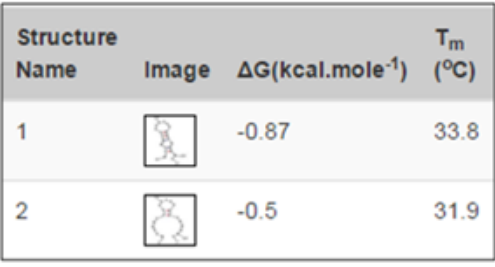

Figura 11. Análise da formação de hairpin.

\section{HRSV 1}

Delta G: $-3.9 \mathrm{kcal} / \mathrm{mole}$ Base Pairs: 3

5'

TTTGGCAATGATAATCTCAAC

|| : : :

3' CAACTCTAATAGTAACGgTTT

HRSV 2

Delta G: $-5.04 \mathrm{kcal} / \mathrm{mole}$ Base Pairs: 4

5

GGGYACAAAGTTGAACACTTC

| |ा।

3' CTTCACAAGTTGAAACAYGGG
HRSV A

Delta G: $-7.05 \mathrm{kcal} / \mathrm{mole}$ Base Pairs: 4

5. GGCTTGTTGCATCTTGTATGATTG

: : ||| : :

3' grtagratgrtctacGtrgrtcGg

HRSV B

Delta G: $-4.41 \mathrm{kcal} / \mathrm{mole}$ Base Pairs: 3

5' GCTAACCCTTTCTGGTGAgAC

$$
::|| \mid \quad:::::
$$

$3^{\prime}$ CAgagtggtctitcccaAtcG

Figura 12. Análise da formação de self dímeros.

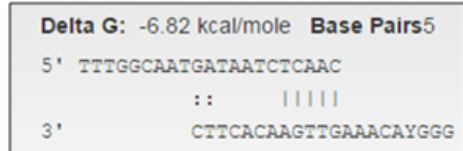

HRSV-1 + HRSV-2

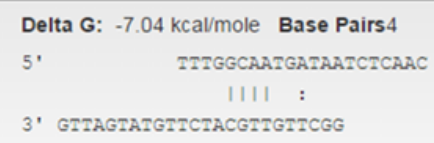

Delta G: $-6.7 \mathrm{kcal} / \mathrm{mole}$ Base Pairs 5

5. tmtggcaatgataatctcaac

3. IIIII :
CAGAGTGGTCTTCCCAATCG

Figura 13. Análise da formação de hetero dímeros. formação de hairpin também se manteve acima de -9 Kcal.mol, com alguns valores positivos, onde a grande maioria não atingiu valores próximos de -2 kcal.mol, o que minimiza a probabilidade de uma possível formação de hairpin. As ferramentas de bioinformática empregadas neste estudo se mostraram suficientes, permitindo a análise do genoma viral e da verificação dos parâmetros que podem levar a formação de estruturas capazes de interferir na eficiência do primer, permitindo 
Tabela 2 . Análise comparativa dos primers.

\begin{tabular}{|c|c|c|c|c|c|c|c|c|c|}
\hline ID & Sequencia & Fonte & Sentido & GC $\%$ & $\operatorname{Tm}^{\circ}$ & $\begin{array}{c}\text { Tamanho } \\
\text { (pb) }\end{array}$ & $\begin{array}{l}\text { Identidade } \\
\text { (BLAST) }\end{array}$ & $\begin{array}{c}\text { Self Dimero } \\
(\Delta G: \text { kcal } / \mathrm{mole})\end{array}$ & $\begin{array}{c}\text { Hairpin } \\
\left(\Delta G:{\left.\text { kcal } / \mathrm{mole}^{-1}\right)}^{2}\right.\end{array}$ \\
\hline 1 & GTCTTACAGCCGTGATTAGG & ABELS et al 2001 & Sense & $50 \%$ & $52.7^{\circ} \mathrm{C}$ & 20 & $100 \%$ & $-3,61$ & $-0,27$ \\
\hline 2 & GGGCTITCTITGGTTACTTC & ABELS et al 2001 & Antisense & $45 \%$ & $51,5^{\circ} \mathrm{C}$ & 20 & $100 \%$ & $-3,14$ & 1.2 \\
\hline 3 & GCTCTTAGCAAAGTCAAGTTGAATGA & HU et al 2002 & Sense & $38,5 \%$ & $55,7^{\circ} \mathrm{C}$ & 26 & $100 \%$ & $-5,47$ & $-1,08$ \\
\hline 4 & TGCTCCGITGGATGGTGTATT & HU et al 2002 & Antisense & $47,6 \%$ & $56,6^{\circ} \mathrm{C}$ & 21 & $100 \%$ & $-4,64$ & $-0,37$ \\
\hline 5 & GATGGCTCTTAGCAAAGTCAAGTTAA & HU et al 2002 & Sense & $38,5 \%$ & $55,4^{\circ} \mathrm{C}$ & 26 & $100 \%$ & $-4,85$ & $-1,6$ \\
\hline 6 & TGTCAATATTATCTCCTGTACTACGTTGAA & HU et al 2002 & Antisense & $33,3 \%$ & $55,5^{\circ} \mathrm{C}$ & 30 & $100 \%$ & $-7,8$ & 0,51 \\
\hline 7 & TGGAAACATACGTGAACAARCTTCA & Jokela et al 2010 & Sense & $38 \%$ & $56,1^{\circ} \mathrm{C}$ & 25 & $96 \%$ & $-9,5$ & -1 \\
\hline 8 & GCACCCATATTGTWAGTGATGCA & Jokela et al 2010 & Antisense & $43,5 \%$ & $55,5^{\circ} \mathrm{C}$ & 23 & $96 \%$ & $-7,05$ & $-1,75$ \\
\hline 9 & GCACCCATATTGTWAGGATGCA & WHILEY et al 2002 & Sense & $43,5 \%$ & $55,5^{\circ} \mathrm{C}$ & 23 & $96 \%$ & $-7,05$ & $-1,75$ \\
\hline 10 & AGCATCACTTGCCCTGAACCATAGGC & WHILEY et al 2002 & Antisense & $53,48 \%$ & $62,9^{\circ} \mathrm{C}$ & 26 & $96 \%$ & $-6,21$ & $-1,67$ \\
\hline 11 & CTGTGATAGARTTCCAACAAAAGAACA & ZLATEVA et al 2007 & Sense & $35,22 \%$ & $54,7^{\circ} \mathrm{C}$ & 27 & $96 \%$ & $-8,27$ & 0,6 \\
\hline 12 & AGTTACACCTGCATTAACACTAAATTCC & ZLATEVA et al 2007 & Antisense & $35,7 \%$ & $55,6^{\circ} \mathrm{C}$ & 28 & $100 \%$ & $-7,05$ & $-0,42$ \\
\hline 13 & GGCTCCAGAATATAGGCATGATTC & ZLATEVA et al 2007 & Sense & $45,8 \%$ & $55,3^{\circ} \mathrm{C}$ & 24 & $100 \%$ & $-5,38$ & $-0,35$ \\
\hline 14 & TGGTTATTACAAGAGCAGCTATACACAGT & ZLATEVA et al 2007 & Antisense & $37,9 \%$ & $57,5^{\circ} \mathrm{C}$ & 29 & $100 \%$ & $-6,34$ & 0,23 \\
\hline 15 & TITGGCAATGATAATCTCAAC & Deste Estudo & Sense & $33,3 \%$ & $48,9^{\circ} \mathrm{C}$ & 21 & $100 \%$ & $-3,9$ & -0.15 \\
\hline 16 & GGCTTGTTGCATCTTGTATGATTG & Deste Estudo & Antisense & $41,7 \%$ & $55^{\circ} \mathrm{C}$ & 24 & $100 \%$ & -7.05 & -1.48 \\
\hline 17 & GCTAACCCTITCTGGTGAGAC & Deste Estudo & Antisense & $52,4 \%$ & $55,3^{\circ} \mathrm{C}$ & 21 & $100 \%$ & -4.41 & -0.87 \\
\hline 18 & GGGYACAAAGTTGAACACTTC & Deste Estudo & Antisense & $45,2 \%$ & $53^{\circ} \mathrm{C}$ & 21 & $95 \%$ & -5.04 & -0.89 \\
\hline
\end{tabular}

assim minimizar erros posteriores, durante a reação de PCR.

Os softwares empregados são todos gratuitos, e facilmente disponíveis, porém exigem um conhecimento prévio de bioinformática. A metodologia descrita concede meios para observar a variabilidade do genoma e mutações presentes em determinadas regiões. O desenho de primers pode também ser empregado no desenvolvimento de primers microssatélites (SAMBROOK; RUSSEL, 2001), ou como em alguns estudos, aplicados no desenho de sondas para PCR em tempo real (HU et al., 2002, JOKELA et al., 2010).

Um bom desenho de primer deve ser priorizado no diagnóstico molecular, pois é imprescindível que estes sejam específicos na detecção do gene de interesse, excluindo a possibilidade de amplificação de regiões inespecíficas, e a formação de estruturas indesejadas como também a não detecção de alguma cepa mutante.

\section{CONCLUSÃO}

O desenvolvimento de primers é extremamente importante para pesquisas moleculares. Por meio de ferramentas de bioinformática obtêm-se resultados satisfatórios quanto a eficiência dos primers na amplificação de sequências de DNA, favorecendo assim o estudo e a prevenção de possíveis erros que interfiram na PCR. Sua utilização representa economia de tempo e de recursos em testes laboratoriais, e concede autonomia ao pesquisador na escolha das regiões que se pretende estudar, com o auxílio de uma gama de dados disponíveis em banco de dados. Outro ponto a ser considerado é que os resultados desse estudo podem servir como orientação a 
pesquisadores na seleção de primers fornecendo uma base dos parâmetros que devem ser levados em conta durante sua análise, e citando algumas das ferramentas disponíveis que possibilitem esta avaliação.

Por conseguinte, os valores obtidos na validação dos primers corroboram para um bom desempenho in vitro, disponibilizado então para uso na deteç̧ão do Vírus Sincicial Respiratório Humano.

\section{REFERÊNCIAS}

$A B E L S$, S. et al. Reliable detection of respiratory syncytial virus infection in children for adequate hospital infection control management. Journal of clinical microbiology, v. 39, n. 9, p. 31353139, 2001.

ALBERTS, B. et al. Molecular biology of the cell (Garland Science, New York, NY). 2002.

ALTSCHUL, S.F. et al. Basic local alignment search tool. Journal of molecular biology, v. 215, n. 3, p. 403-410, 1990.

ALVAREZ, A.E. et al. Epidemiological and genetic characteristics associated with the severity of acute viral bronchiolitis by respiratory syncytial virus. Jornal de pediatria, v. 89, n. 6, p. 531-543, 2013.

ARBEX, W.; COSTA, V.S.; SILVA, M.V.G. Bioinformática como ferramenta nas pesquisas atuais. Anais do III Encontro de Genética e Melhoramento, Viçosa, UFV, 2006.

BEASLEY, E.M. et al. PCR Applications: Protocols for Functional Genomics, Academic press, p. 55-71, San Diego, 1999.

BEEM, M. et al. Association of the chimpanzee coryza agent with acute respiratory disease in children. New England Journal of Medicine, v. 263, n. 11, p. 523-530, 1960.

BERMAN, S. Epidemiology of acute respiratory infections in children in developing countries. Revista infectious disease, v. 13, 1991.

BRASIL. MINISTÉRIO DA SAÚDE. Manual de normas para infecção respiratória aguda. Sociedades brasileiras de pediatria e pneumologia, p. 1-27, 1991.

BROWN, T.A. Clonagem gênica e análise de DNA: uma introdução. Artmed, 4ed, 240p, 2003.

BUTLER, J.M.; RUITBERG, C.M.; VALLONE, P.M. Capillary electrophoresis as a tool for optimization of multiplex PCR reactions. Fresenius' journal of analytical chemistry, v. 369, n. 3 , p. 200-205, 2001.

CAVALCANTI, M.P.C. et al. AVANÇOS BIOTECNOLÓGICOS PARA O DIAGNÓSTICO DAS DOENÇAS NFECCIOSAS E PARASITÁRIAS. Revista de patologia tropical, v. 37, n. 1, p. 01-14, 2008.

COIRAS, M.T. et al. Simultaneous detection of influenza A, B, and C viruses, respiratory syncytial virus, and adenoviruses in clinical samples by multiplex reverse transcription nested-PCR assay. Journal of medical virology, v. 69, n. 1, p. 132-144, 2003.
DUNN, James J.; MILLER, Melissa B. Emerging respiratory viruses other than influenza. Clinics in laboratory medicine, v. 34, n. 2, p. 409-430, 2014.

EXPASY. Bioinformatics Resource Portal. Viral zone. Disponível em: <http://viralzone.expasy.org/>. Acesso em 20 ago. 2015. 19:50:23.

HACKING, Doug; HULL, J. Respiratory syncytial virus-viral biology and the host response. Journal of infection, v. 45, n. 1, p. 18-24, 2002.

HALL, Caroline Breese; DOUGLAS, R. Gordon. Modes of transmission of respiratory syncytial virus. The journal of pediatrics, v. 99, n. 1, p. 100-103, 1981.

HAMMITT, Laura L. et al. Added value of an oropharyngeal swab in detection of viruses in children hospitalized with lower respiratory tract infection. Journal of clinical microbiology, v. 49, n. 6, p. 23182320, 2011.

HU, Aizhong et al. Simultaneous detection, subgrouping, and quantitation of respiratory syncytial virus $A$ and $B$ by real-time PCR. Journal of clinical microbiology, v. 41, n. 1, p. 149-154, 2003.

JOKELA, P. et al. Detection of human metapneumovirus and respiratory syncytial virus by duplex real-time RT-PCR assay in comparison with direct fluorescent assay. Clinical microbiology and infection, v. 16, n. 10, p. 1568-1573, 2010.

KOPELMAN, B. I; MIYOSHI, M. H. Infecção pelo vírus sincicial respiratório. Pediatria moderna, v.35, n. 4, p. 233-9, 1999.

KUBISTA, Mikael et al. The real-time polymerase chain reaction. Molecular aspects of medicine, v. 27, n. 2, p. 95-125, 2006.

LEHNINGER, A. L.; NELSON, D. L.; COX, M. M. Princípios de bioquímica. Sarvier, p.839, São Paulo, 2000.

MACEDO, Silvia Elaine Cardozo et al. Infecção pelo vírus respiratório sincicial em crianças menores de um ano de idade internadas por doença respiratória aguda em Pelotas, RS. Jornal de pneumologia. v.29, n. 1, p. 4-8, 2003.

MACHADO, Daniela Bandeira Brancante et al. Identificação e caracterização molecular do virus sincicial respiratório humano em crianças com infecções respiratórias de 2006 a 2010. 2012. Tese de Doutorado. Instituto Oswaldo Cruz.

MINALI, C.C.; DEBUR, M. do C.; FERRARI, L.P. Comparação entre as técnicas de imunofluorescencia indireta e PCR Multiplex para detecção de vírus respiratórios. Saúde, v. 1, n. 9, 2014.

MIYAO, C.R. et al. Infecções virais em crianças internadas por doença aguda do trato respiratório inferior. J Pediatr (Rio J), v. 75, n. 5, p. 334-44, 1999.

MOURA, F. E. A. et al. Estudo de infecções respiratórias agudas virais em crianças Aceito para publicação em 28/01/03 atendidas em um centro pediátrico em Salvador (BA). Jornal brasileiro de patologia e medicina laboratorial. Rio de Janeiro, ed. 4, v.39, p. 275-282, 2003.

MULLIS, K.B. et al. The unusual origin of the polymerase chain reaction. Scientific American, v. 262, n. 4, p. 56-61, 1990.

NCBI: National Center for Biotechnology Information Disponível em: <http://www.ncbi.nlm.nih.gov/>. Acesso em 20 agos. 2015. 16:15:48.

PEARSON, W.R.; LIPMAN, D.J. Improved tools for biological sequence comparison. Proceedings of the National Academy of Sciences, v. 85 , n. 8, p. 2444-2448, 1988.

PERANCONI, D.S. Alinhamento de seqüências biológicas em arquiteturas com memória distribuída. 2005. Dissertação de mestrado. Universidade do Vale do Rio dos Sinos. 
SAMBROOK, J. et al. Molecular cloning: a laboratory manual. Cold spring harbor laboratory press, 1989.

SANTORO, A. Caracterização e validação de marcadores microssatélites para golfinhos-rotadores (Stenella longirostris). 2008. Trabalho de Conclusão (Bacharelado - Ciências Biológicas). Universidade Estadual Paulista

SETUBAL, J.C.; MEIDANIS, J.; SETUBAL-MEIDANIS. Introduction to computational molecular biology. PWS Pub., 1997.

SMITH, C.L.; CANTOR, C.R. [28] Purification, specific fragmentation, and separation of large DNA molecules. Methods in enzymology, $v$. 155, p. 449-467, 1987.

SUTMÖLLER, F. et al. Etiology of acute respiratory tract infections among children in a combined community and hospital study in Rio de Janeiro. Clinical infectious diseases, v. 20, n. 4, p. 854-860, 1995.

WANG, X.; SEED, B. A PCR primer bank for quantitative gene expression analysis. Nucleic acids research, v. 31, n. 24, p. e154-e154, 2003.

WELLIVER, R.C. Respiratory syncytial virus immunoglobulin and monoclonal antibodies in the prevention and treatment of respiratory syncytial virus infection. In: Seminars in perinatology. WB Saunders, 1998. p. 87-95.

WHILEY, D.M. et al. Detection of human respiratory syncytial virus in respiratory samples by LightCycler reverse transcriptase PCR. Journal of clinical microbiology, v. 40, n. 12, p. 4418-4422, 2002.

WILLIAMS, B.G. et al. Estimates of world-wide distribution of child deaths from acute respiratory infections. The Lancet infectious diseases, v. 2, n. 1, p. 25-32, 2002.

ZLATEVA, K.T. et al. Subgroup prevalence and genotype circulation patterns of human respiratory syncytial virus in Belgium during ten successive epidemic seasons. Journal of clinical microbiology, v. 45, n. 9, p. 3022-3030, 2007

Citar esse artigo: Queiroz JAS, Alves LS, Dall'acqua DSV, Souza LFB. Desenho e Validação de Primers In Silico para Detecção do Vírus Sincicial Respiratório Humano. RevFIMCA 2017;4(1):17-30.

Autor para Correspondência: Jackson Alves da Silva Queiroz, queiroz.jas@gmail.com

Recebido em: 21 Agosto 2017

Aceito em: 03 Novembro 2017 